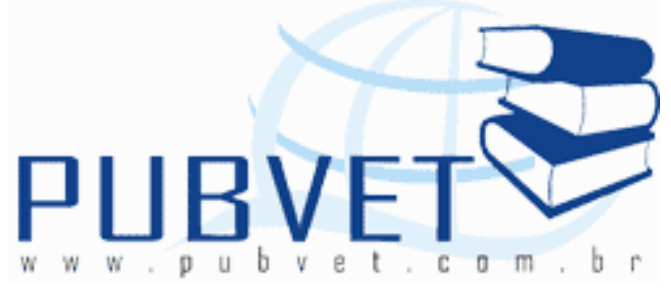

PUBVET, Publicações em Medicina Veterinária e Zootecnia.

\title{
Principais causas de condenação de rins de bovinos que foram abatidos no Matadouro Municipal de Itabuna, Bahia
}

Jéssica Santos Tigre ${ }^{1}$; Pedro Alexandre Gomes Leite ${ }^{2}$; Roberta Costa Dias ${ }^{2}$

${ }^{1}$ Mestre em Ciência Animal pela Universidade Estadual de Santa Cruz - UESC. (UESC), Ilhéus-BA. jtigre@live.com;

${ }^{2}$ Docente do curso de Medicina Veterinária, Departamento de Ciências Agrárias e Ambientais - DCAA/UESC.

\section{Resumo}

A inspeção de bovinos em matadouros é importante, pois o conhecimento de patologias encontradas durante 0 abate permite a seleção de carcaças que apresentam melhor qualidade e o diagnóstico de doenças que podem ser transmitidas pelo consumo. Foi acompanhado o abate de 1002 bovinos, no Matadouro Municipal da cidade de Itabuna, Bahia. Foram avaliados 2004 rins, destes, 980 foram condenados. Os animais abatidos tinham idade entre 24 e 36 meses, não sendo feita diferenciação entre machos e fêmeas. Das patologias encontradas durante avaliação dos rins, a mais frequente correspondeu aos cistos urinários $(45,9 \%)$, seguido pela presença de lesões características de nefrite $(38,7 \%)$. Outras condenações ocorreram devido a alterações circulatórias como congestão $(10,2 \%)$ e infarto $(5,2 \%)$. Não foram observadas condenações causadas por erro de manejo das peças. Com este trabalho objetivou-se descrever os principais motivos de condenação de rins de 
bovinos que foram abatidos no Matadouro Municipal de Itabuna, Bahia, através de avaliação macroscópica durante a inspeção sanitária.

Palavras-chave: bovinos, inspeção, rins

\title{
Main reasons for condemnation of kidneys from cattle that were slaughtered at the Municipal Abattoir Itabuna, Bahia
}

\begin{abstract}
Inspection of cattle slaughterhouses is important because knowledge of conditions found during slaughter allows the selection of carcasses that have better quality and diagnosis of diseases that can be transmitted by consumption. It was accompanied by the slaughter of cattle in 1002 in the City of Slaughterhouse Itabuna, Bahia. 2004 kidneys were evaluated, of whom 980 were convicted. The slaughtered animals were aged between 24 and 36 months, and there was no difference between males and females. Found during the evaluation of diseases of the kidneys, the more frequent bladder weakness corresponding to cysts $(45.9 \%)$, followed by lesions characteristics of nephritis (38.7\%). Other convictions occurred due to circulatory changes as congestion (10.2\%) and stroke (5.2\%). There were no convictions caused by error handling parts. This work aimed to describe the main reasons for condemnation of kidneys from cattle that were slaughtered at the Municipal Abattoir Itabuna, Bahia, through macroscopic evaluation during the sanitary inspection.
\end{abstract}

Keywords: cattle, inspection, kidneys

\section{INTRODUÇÃO}

Segundo o Instituto Brasileiro de Geografia e Estatistica (IBGE) o Brasil apresenta posição de destaque no mercado mundial de produção de carnes, além de possuir o maior rebanho comercial do mundo, que em 2011 chegou a mais de 209 milhões de cabeças, representado 40\% do valor do PIB (Produto Interno Bruto) agropecuário e $26 \%$ da força de trabalho rural, mundialmente 
TIGRE, J.S., LEITE, P.A.G. e DIAS, R.C. Principais causas de condenação de rins de bovinos que foram abatidos no Matadouro Municipal de Itabuna, Bahia. PUBVET, Londrina, V. 6, N. 24, Ed. 211, Art. 1409, 2012.

apresenta-se em primeiro lugar nas exportações de carne bovina. A produção nacional de cabeças de gado no Brasil encontra-se hoje concentrada principalmente na região Sudeste, seguida pela região Centro-Oeste e Sul do país. No ano de 2011 , foram abatidas 28,8 milhões de cabeças de bovinos, queda de $1,6 \%$ em relação a 2010 . Os elevados preços da carne bovina no mercado interno e o aumento do consumo das carnes de suínos e de aves indicam que o consumidor pode ter substituído parcialmente o consumo da carne bovina por carnes com preços mais acessíveis. A queda nas exportações devido à crise econômica na Europa, à desaceleração econômica global e a necessidade de reposição do rebanho nacional são outros fatores que contribuíram para este resultado.

A Inspeção Sanitária em matadouros de bovinos constitui uma importante ferramenta para identificação de doenças que ocorrem em determinada região. A avaliação dos órgãos é feita através da visualização macroscópica e ocorre na sala de matança, sendo realizada pelo Médico Veterinário responsável. Quando alguns órgãos ou carcaças não se encontram no padrão estabelecido, elas são condenadas (BRASIL, 1971).

Um dos órgãos com maiores perdas em matadouros são os rins, alterações importantes como cistos urinários, nefrites, congestão e infartos podem ser identificadas através da avaliação macroscópica. De acordo com Prata \& Fukuda (2001), os rins são examinados por visualização e, se necessário por palpação e realização de incisões.

Este trabalho teve como objetivo relatar as principais causas de condenação de rins de bovinos que foram abatidos no Matadouro Municipal de Itabuna, Bahia, através da avaliação macroscópica de rins condenados pela inspeção sanitária.

\section{MATERIAL E MÉTODOS}

Este estudo foi realizado no Matadouro Municipal de Itabuna, Bahia, no período de 30 de maio a 19 de Setembro de 2009, neste período foi acompanhado o abate de 1002 bovinos, onde foram avaliados 2004 rins, entre órgãos direitos e esquerdos de animais de ambos os sexos com idade variando entre 24 e 36 
meses, que segundo avaliação da Guia de Transporte Animal (GTA), emitida pela Agência de Defesa Animal da Bahia (ADAB), são provenientes das regiões Sul e Sudoeste da Bahia, vacinados contra a Febre Aftosa, Brucelose e raiva. $\mathrm{Na}$ linha de inspeção de rins, todos os órgãos foram inspecionados e aqueles que apresentaram lesões, foram avaliados e suas alterações registradas.

\section{RESULTADOS E DISCUSSÃO}

Dos 2004 rins avaliados macroscopicamente 980 foram condenados (49\%) e 1024 foram liberados para o consumo (51\%). A condenação dos rins pela presença de cistos urinários representou $45,9 \%$ do total de condenações. Quando avaliados os cistos urinários caracterizam-se pela presença de cavidades císticas medindo de 0,3 a 0,6 mm de diâmetro e ausência de tecido renal (Figura 1). A principal causa de condenação dos rins é devido à presença de cistos urinários que podem se apresentar como solitários ou múltiplos quando são chamados de policistos, fazendo com que os órgãos apresentem um aspecto de "queijo suíço" (Thomson, 1983).

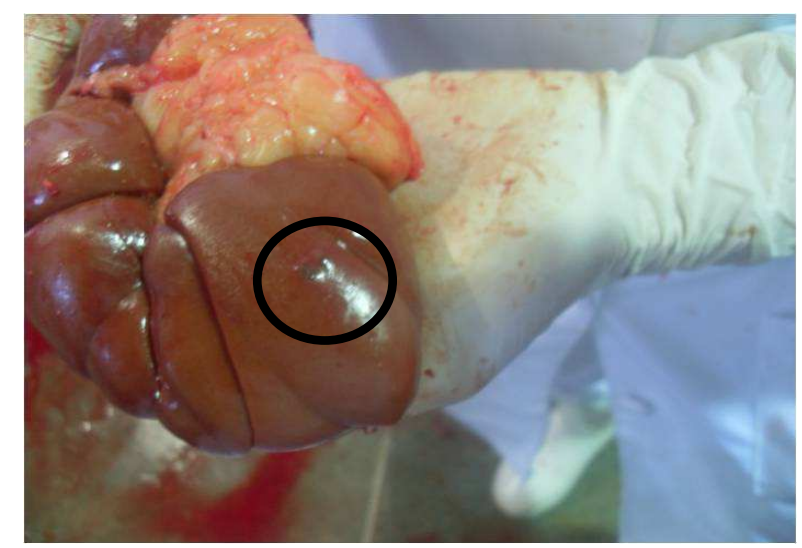

Figura1 - Cisto renal representado pela ausência de tecido renal.

Resultado muito parecido ao presente estudo foi encontrado por Batista (2008), avaliando condenações de vísceras de bovinos em Matadouros Frigoríficos no estado do Espírito Santo, o autor observou que a condenação 
dos rins pela presença de cistos urinários chegou a 40,5\%, já no estudo feito por Mendes (2009), os cistos urinários provocaram um descarte em 35,04\% dos rins avaliados na inspeção sanitária.

Segundo Loretti et al. (2003), a baixa quantidade de fibra, a ingestão limitada de água e os níveis elevados de fósforo na ração correspondem a fatores associados com a formação de urólitos ocasionando cistos urinários.

Outra causa de condenação foi à presença de lesões características de nefrite, totalizando $38,7 \%$ dos rins condenados (Figura 2), Lima et al. (2007), através da avaliação das alterações anatomopatológicas durante a inspeção de rins de bovinos, encontrou 25\% de rins descartados por nefrites. Cheville (1994), avaliando macroscopicamente, observou que nas nefrites agudas os rins podem se apresentar tumefeitos e pálidos.

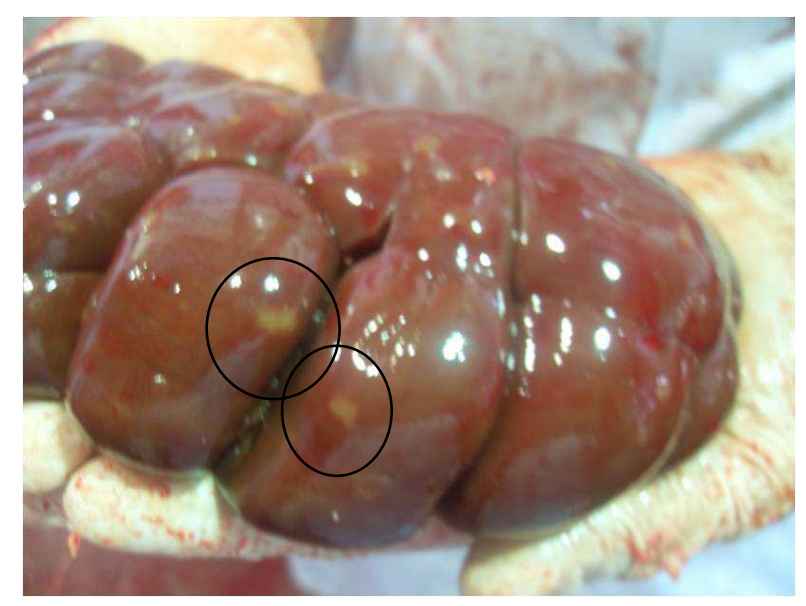

Figura 2 - Órgão caracterizado na avaliação macroscópica com pequenos pontos brancos caracterizados como nefrite.

Na espécie bovina, observa-se durante o abate a ocorrência de nefrite do tipo intersticial, sendo esta raramente identificada como uma causa de doença clínica em animais pecuários (Radostits et al. 2002).

Outras causas de condenação observadas foram lesões compatíveis com congestão representado um total de $10,2 \%$, seguido por infarto $5,2 \%$. 
TIGRE, J.S., LEITE, P.A.G. e DIAS, R.C. Principais causas de condenação de rins de bovinos que foram abatidos no Matadouro Municipal de Itabuna, Bahia. PUBVET, Londrina, V. 6, N. 24, Ed. 211, Art. 1409, 2012.

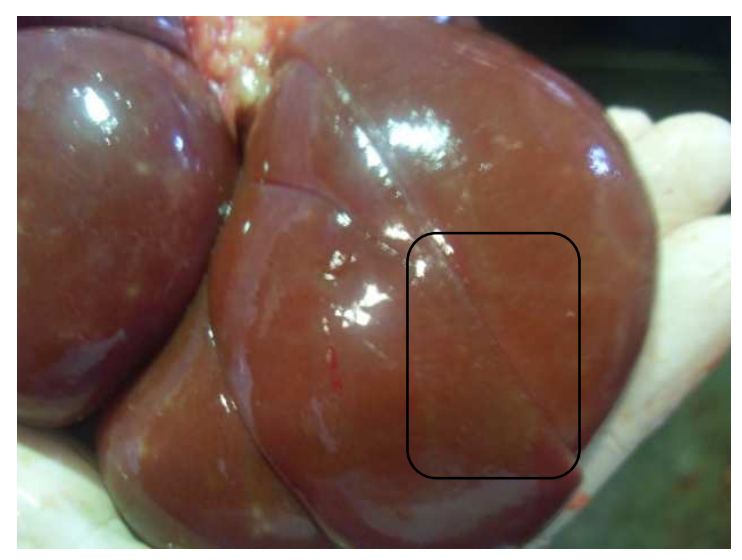

Figura 3 - Área de infarto em órgão condenado.

Castro (2010), avaliando as ocorrências patológicas encontradas em rins de bovinos, observou que a congestão é um achado comum em matadouros, macroscopicamente o órgão apresenta-se aumentado de volume com coloração escura e ao corte observa-se acúmulo de sangue no parênquima renal, neste estudo a condenação por congestão chegou a um total de 20,94\%, estando entre as principais causas de condenação. Também avaliando rins, Mendes et al. (2009), observou que não era frequente a presença de infartos nos rins dos animais abatidos encontrando um total de $9,4 \%$ das condenações.

\section{CONCLUSÃO}

Através desse estudo podemos observar que as principais causas de condenação ocorreram devido a alterações como Cistos e Nefrite, como observado em outros trabalhos estas foram causas relevantes seguindo os mesmos parâmetros de condenação, indicando que estas não são causas locais, mas se repetem ao longo das condenações realizadas nos matadouros frigoríficos. Desta forma, torna-se necessário a presença do Médico Veterinário nestes estabelecimentos impedindo que chegue a mesa do consumidor produtos de baixa qualidade, bem como, impedir a disseminação de doenças veiculadas por produtos de origem animal que poderiam colocar em risco a saúde pública. 


\section{REFERÊNCIAS BIBLIOGRÁFICAS}

BATISTA, A. T. Quantificações das condenações em vísceras de bovinos em 2007 nos matadouros-frigoríficos do estado do espírito santo registrados no serviço de inspeção estadual. Vitória (ES). 2008. 22 folhas. Tese (Mestrado em Higiene e Inspeção de Produtos de Origem Animal) UCB, Vitória, 2008.

BRASIL. Ministério da Agricultura Pecuária e Abastecimento/DIPOA. Inspeção de carnesPadronização de Técnicas, instalações e equipamentos-Bovinos: Currais e seus Anexos. Brasília: Alvorada, 1971.

CASTRO, R.V. Ocorrências patológicas encontradas de rins e fígado bovinos em matadouro frigorifico do triângulo mineiro. FAZU. v. 7, p. 159-163, 2010.

CHEVILLE, N. F. Patologia celular. Zaragoza: Acribia, 1980. 214p.

Instituto Brasileiro de Geografia e Estatística-IBGE, Disponível em:<http://www.ibge.gov.br/home/estatistica/economia/agropecuaria/censoagro/default.sht m> acesso em: 09 de abril de 2012.

LIMA, M.F.C.; SUASSUNA, A.C.D.; AHID, S.M.M. et al. Análise das alterações anatomopatológicas durante a inspeção post mortem em bovinos no abatedouro frigorífico industrial de Mossoró, Rio Grande do Norte. Ciência Animal. v. 14, n. 2, p. 113,116, 2007.

LORETTI, A. P.; OlIVEIRA, L. O.; CRUZ, C. E.F. et al. Clinical and pathological study of an outbreak of obstructive urolithiasis in feedlot cattle in southern Brazil. Pesquisa Veterinária Brasileira, v.23, n.2, p.61-64, 2003.

MENDES, E. R. ; MOREIRA, F. ; ROCHA, C.S. ; PILATI, C. Estudo morfológico de rins de bovinos abatidos em frigoríficos industriais sob inspeção estadual no Oeste e Planalto Catarinense, Brasil.Ciência Animal Brasileira. v10, n1, p. 281-287, 2009.

RADOSTITS, O. M.; GAY, C. C.; BLOOD, D. C.;HINCHCLIFF, K.W. Clínica veterinária: um tratado de doenças dos bovinos, ovinos, suínos, caprinos e eqüinos. 9 ed. Rio de Janeiro: GuanabaraKoogan, 2002. 1737p.

PRATA, L. F.; FUKUDA, R. T. Fundamentos de Higiene e Inspeção de Carnes, Jaboticabal: Funep, 2001, 326p.

THOMSON, R. G. Patologia Geral Veterinária. Rio de Janeiro, Ed. Koogan, 1983, 412 p. 